\title{
Investigando con familiares de migrantes desaparecidos: de objetos/sujetos de estudio a coproductores de conocimiento*
}

\author{
Working with families of disappeared migrants: \\ from objects/subjects of study to knowledge producers
}

\author{
GABRIELA MARTÍNEZ CASTILLO**
}

\begin{abstract}
Across Mexico and Central America, families of disappeared/missing persons are demanding to play a more active role in the articulation of the academic, journalistic, psychological, and humanitarian narratives that are being built upon their experience and struggles. This article describes the methodological dimension of a research project which gradually turned into a collaborative endeavour following the explicit demand of fifteen members of the Salvadoran Committee of Families of Deceased and Disappeared Migrants (Cofamide). As a result, Cofamide's members positioned themselves as knowledge producers, defining the research questions and co-analysing the data produced in order to rethink the political work developed by the Committee. Hence, the project problematized the epistemic violence of the traditional subject-object divide in research by using an assemblage of methodologies; such as Participatory Action Research, collaborative methods, and Black and Community Feminist approaches. The article will also discuss some key challenges and limitations faced throughout this process.
\end{abstract}

Key words: participatory / collaborative methodologies, intersectionality, disappearance, migration, violences

\begin{abstract}
Resumen
Las familias de personas desaparecidas demandan una participación más activa en la construcción de las narrativas que les abordan, sean éstas teóricas, periodísticas, psicológicas, humanitarias o de derechos humanos. Aquí se describe el recorrido de una investigación que inició con métodos y objetivos tradicionales, pero que a exigencia de quince familiares de migrantes desaparecidos, vinculados al Comité de Familiares de Migrantes Fallecidos y Desaparecidos de El Salvador (Cofamide), se transformó gradualmente en una colaboración donde ellas y ellos se posicionaron como coproductores de conocimiento, al responder y analizar colectivamente las preguntas que plantearon para [re]pensar sus búsquedas y sus exigencias de justicia. Para sostener su participación, recurrimos a metodologías que problematizan la violencia epistémica constitutiva de la jerarquía investigador-sujeto / objeto de estudio (investigación acción participativa, metodologías colaborativas, feministas negras y comunitarias). Exploramos cómo las investigaciones pueden aportar a los objetivos políticos de los familiares y revitalizar a la academia, así como sus limitaciones y desafios.

Palabras clave: metodologías participativas y colaborativas, interseccionalidad, desaparición, migración, violencias
\end{abstract}

\footnotetext{
* Trabajo recibido el 18/03/21 y aceptado el 19/05/21. Este trabajo fue escrito en el marco de la Beca de investigación "Migraciones y Movilidad Humana Edelberto Torres Rivas", 2019-2020, del Consejo Latinoamericano de Ciencias Sociales.

** Universidad Autónoma Metropolitana-Iztapalapa, Departamento de Antropología. Av. San Rafael Atlixco 186, col. Vicentina, Iztapalapa, 09340 Ciudad de México <gabriela.martcast@gmail.com>; orciD: https: / /orcid.org/0000-0002-2485-4225
} 
¿. Cuál es el papel de las y los investigadores ante las violencias que vivimos en México y Centroamérica?, ¿qué lugar ocupan nuestras investigaciones en este contexto?, ¿existen por fuera de la academia y de las universidades?, ¿deberían?

En 2017, quince integrantes del Comité de Familiares de Migrantes Fallecidos y Desaparecidos de El Salvador (Cofamide) ${ }^{1}$ y yo comenzamos un proceso de investigación colectiva, donde nos hicimos preguntas similares, en sus palabras: “¿para qué nos sirve que vengan a entrevistarnos?"

Al principio dijeron que sí encontraban alguna utilidad, habría difusión sobre los casos de sus migrantes desaparecidos y quizá eso contribuiría a ampliar las posibilidades de encontrarlos y de alcanzar justicia. Sin embargo, durante el primer taller que llevamos a cabo en abril de ese mismo año, Roberta Pineda ${ }^{2}$ compartió con mucha honestidad su opinión sobre las investigaciones que les abordan, incluida la mía:

¿Por qué todos los que vienen nos preguntan lo mismo?, periodistas, de las universidades, abogados, ¿por qué será que quieren saber lo mismo? No nos preguntan cómo estamos, qué sentimos, qué pensamos, qué necesitamos, qué hacemos para aguantar, qué hacemos para seguir. [...] La búsqueda no es fácil y a veces hasta es peligroso. Y cuando hablamos nos dicen que estamos mal, que lo que decimos está equivocado, que no es importante para lo que se está hablando.

Como la investigación colectiva formaba parte de mi trabajo doctoral (2016-2021), en un principio yo elegí los temas de análisis, que fueron aprobados por Cofamide antes de empezar el trabajo. No obstante, el discurso de Roberta catalizó otras participaciones que expusieron más dudas y limitaciones. La conversación derivó en la elección de un tema distinto y nuevas preguntas de investigación, más útiles y significativas para los objetivos del Comité.

Mi propuesta original pretendía mapear las búsquedas y exigencias de justicia transnacionales emprendidas por el Comité, así como las respuestas y reacciones de los Estados salvadoreño, mexicano y estadounidense ante la desaparición de migrantes y las reivindicaciones reclamadas por las familias. Em- pero, las y los participantes no estaban interesados en estudiar únicamente sus propias prácticas y las respuestas de los Estados, pues son los temas que más tratan en sus reflexiones cotidianas.

En ese momento, para Cofamide era más importante, por un lado, analizar por qué los actores solidarios que les acompañaban tenían dificultades para colaborar entre sí, y, por el otro, diseñar estrategias para que las familias participaran de manera más protagónica en el diseño y planeación de las acciones conjuntas. Por actores solidarios/aliados entendemos a las organizaciones no gubernamentales (ONG), organismos internacionales, expertos en derechos humanos, financiadoras, periodistas, Iglesias y, por supuesto, académicos que intervienen en la problemática de la desaparición de migrantes en la ruta CentroaméricaMéxico-Estados Unidos.

Las familias tienen claro su papel frente a los Estados, exigen que les reconozcan como sujetos de derechos, como personas con dignidad, y como agentes que piden cambios en las instituciones que son omisas, permiten e incluso cometen las desapariciones de sus seres queridos. A pesar de ello, había confusión en cuanto a su rol con los actores solidarios que se acercaban al Comité, en especial tenían dudas sobre las estrategias más pertinentes para expresar sus desacuerdos o conflictos respecto a las ayudas ofrecidas, temían que ante opiniones diferentes los aliados retiraran su apoyo. Esto les preocupaba pues, aunque podían no estar de acuerdo totalmente con ellos, reconocían la importancia de las colaboraciones y la vinculación en redes.

En este escenario, un análisis sobre las agendas, apuestas políticas, ideologías, recursos e intereses de los actores solidarios contribuiría a que las familias ubicaran el lugar que querían/necesitaban ocupar dentro de la sociedad civil transnacional; al mismo tiempo, brindaría insumos para promover la articulación entre los aliados, requisito indispensable para aumentar la fuerza política de las familias frente a los Estados.

Con este nuevo tema se hace evidente que las y los integrantes de Cofamide reconocen las relaciones asimétricas entre aliados, y cuestionan las posturas de neutralidad y objetividad que algunos enarbolan como parte de su identidad. Los actores solidarios

\footnotetext{
1 "Cofamide nace en el año 2006 como una iniciativa de madres, padres, esposas, hijos, en fin, de familiares de migrantes que emprendieron un día su camino hacia los Estados Unidos y de los que nunca volvieron a saber" <http: / cofamide. blogspot.com/p/about-cofamide.html> [9 de agosto de 2020]. Su misión es "contribuir en la búsqueda y localización de migrantes que fallecen o desaparecen en tránsito hacia los Estados Unidos, e incidir ante las autoridades competentes para que se garantice la protección y respecto a su integridad humana" < https://www.facebook.com/pg/Cofamide/ about/?ref=page_internal> [9 de agosto de 2020].

2 Por cuestiones de seguridad, no se mencionan nombres reales ni detalles que puedan identificar a los familiares ni a sus migrantes desaparecidos.
} 
también estamos inmersos en sistemas de poder que influyen en nuestras decisiones al momento de optar por ciertas estrategias de búsqueda y exigencia de justicia en detrimento de otras. Ignorar las jerarquías entre amigos debilita las articulaciones $\mathrm{y}$, por lo tanto, el alcance de las luchas conjuntas. ${ }^{3}$

También muestra que, si bien hay situaciones donde los familiares se sienten cómodos siendo representados, existen otras en las cuales quisieran asumir papeles más activos tanto en la implementación de acciones como en los procesos de análisis, planeación y diseño de las mismas, de tal modo que se garantice que sus necesidades y objetivos son respetados y tomados en cuenta dentro de las estrategias compartidas.

En un contexto donde la investigación tenía como objetivo generar insumos para fortalecer la presencia protagónica de las familias, el proceso mismo debía construirse con su involucramiento y visibilizando con claridad sus contribuciones. Para tal fin, recurrimos a ensamblajes metodológicos que garantizaran la participación de las familias como interlocutoras en la teorización de conceptos y narrativas, y tratamos de alejarnos de aquellos que podrían colocarlos de manera exclusiva como informantes dadores de materia prima.

Aquí cabe una aclaración importante. Recurrir a un ensamblaje de métodos mixtos fue indispensable para alcanzar los objetivos planteados en este contexto, pero no propongo que sea el único camino valido/ apropiado que tiene la academia para solidarizarse con las familias de personas desaparecidas. Ni todas las investigaciones participativas o colaborativas generan resultados para los grupos que pretenden apoyar, ni todas las investigaciones que recurren a métodos tradicionales, como la entrevista y la observación participante, son únicamente extractivistas, inútiles más allá de la universidad o implican falta de compromiso.

La trascendencia de la reflexión metodológica radica no sólo en preguntarse ¿cómo investigo?, sino también ¿en qué contextos y con qué fines se diseñan los problemas de investigación y las formas en que pretendo abordarlos?, ¿qué implicaciones tendrá para los involucrados?, ¿se inserta la investigación, aunque sea por un periodo corto, en la práctica política de los participantes no académicos? y ¿cómo lo hace? Nuestra colaboración partió de reconocer que el "método no es y nunca podría ser inocente o sólo técnico [..., ya que] inevitablemente produce no sólo verdades y no-verdades, realidades y no-realidades, presencias y ausencias, sino también arreglos con implicaciones políticas" (Law, 2004: 143),
Este artículo relata el proceso metodológico de la investigación colectiva que llevamos a cabo intermitentemente de 2017 a 2019, mediante la cual quince integrantes de Cofamide dejaron lejos el papel de informantes para ubicarse como coproductores de conocimiento. Plantea y responde tres preguntas que sostuvieron en lo concreto nuestra colaboración: ¿qué metodologías necesitamos para garantizar que las y los familiares se mantengan como coinvestigadores?, ¿qué hacemos para identificar e intervenir en las relaciones de poder que dificultan la colaboración activa de todas y todos?, ¿quiénes han hecho cosas similares y qué podemos aprender de sus experiencias?

\section{¿Qué metodologías necesitamos para garantizar que las y los familiares se mantengan como coinvestigadores?}

Que las y los salvadoreños se ubicaran como coinvestigadores abrió puertas para explorar metodologías comprometidas con los procesos de liberación, emancipación, justicia social y/o derechos humanos que, aunque en América Latina han sido usadas históricamente por la academia militante, ocupan un lugar periférico dentro de las ciencias sociales.

La investigación acción participativa (IAP) (Fals Borda, 1978) fue el principal referente, pues nos ayudó a: a) configurar la construcción de conocimiento como un espacio de aprendizaje y reflexión para todos, no sólo para mí como investigadora; $b$ ) revalorar el conocimiento popular explicitando que los académicos y demás actores solidarios no son los únicos actores con la capacidad para generar saberes útiles/importantes, y reconociendo que las búsquedas por los desaparecidos son espacios de aprendizaje y teorización; $c$ ) identificar las consecuencias de la dicotomía investigador-sujeto de estudio y cómo abordarla; y d) aportar flexibilidad, ya que la IAP contempla la redefinición constante de los límites de la investigación, como resultado de la colaboración continúa se espera que las preguntas y temas se reconfiguren conforme avanzan los análisis colectivos.

Más adelante nos acercamos a las metodologías colaborativas (Rappaport, 2008), y aunque coinciden casi en todo con la IAP, decidimos diferenciarlas por dos razones. Primero, porque nos pareció que la producción literaria de lo colaborativo explica con más claridad pasos, tensiones, desacuerdos y dificultades de las investigaciones conjuntas (Arribas Lozano, 2018; Rappaport, 2020).

3 Para conocer más sobre los resultados de la investigación colectiva consúltese Martínez Castillo, 2020. 
Y, segundo, porque para nosotros la participación y la colaboración no significan lo mismo. Ambas metodologías comparten compromisos políticos y de hecho se originan como parte de los procesos de reflexión de las organizaciones indígenas y campesinas colombianas. Sin embargo, en el contexto de los comités de familias de migrantes desaparecidos, las técnicas participativas son un recurso usado por actores no gubernamentales, estatales e internacionales para extraerles información para sus propios fines, alejados por completo de los principios políticos fundacionales de la investigación acción participativa.

Desde su experiencia como sujetos de intervenciones humanitarias, de derechos humanos, psicológicas, forenses, de cooperación internacional, académicas, etcétera, las familias ubican a la participación como una actividad donde son meros asistentes, aunque hablen mucho. Entonces, elegimos usar la palabra colaboración para diferenciar las iniciativas donde ellas y ellos se involucran protagónicamente en la toma de decisiones del diseño, planeación, implementación y evaluación de las estrategias.

En este sentido, también llamamos metodologías colaborativas a los procesos que las y los integrantes de Cofamide fueron creando de manera independiente a la investigación colectiva. Algunos empezaron a diseñar sus propias investigaciones, a hacer entrevistas, visitas a campo y a escribir sus propios textos. Lo que derivó en un proyecto de libro colectivo escrito por tres personas de El Salvador y dos de Honduras -quienes se sumaron después-, donde las reflexiones de las y los familiares aparecen en primera persona, sin in- terpretaciones ni mediaciones y desde un análisis que va más allá de lo testimonial, uno de los deseos más importantes para este caminar conjunto.

Sus trabajos tratan: a) la vinculación entre desapariciones y movimientos sociales del pasado con los presentes; $b$ ) el análisis de mecanismos que invisibilizan la desaparición de migrantes; c) la recuperación de la búsqueda y exigencia de justicia como un proceso de aprendizaje político; d) la sistematización de aportes para la reconstrucción del tejido social de sus comunidades; y e) la ampliación de los conceptos de justicia para que incluyan estrategias que les devuelvan las oportunidades y condiciones que las familias tendrían si su ser querido no hubiera desaparecido.

Nuestra investigación se conecta también con metodologías producidas por feministas negras estadounidenses y comunitarias latinoamericanas, no porque los familiares involucrados se consideren a sí mismos feministas, sino porque la interseccionalidad, aporte de esta corriente de pensamiento (Crenshaw, 1991), amplió muchísimo el análisis de las relaciones de poder que configuran/legitiman las dicotomías investigador-investigado, teoría-práctica, conocimiento académico-conocimiento no académico, y además nos ayudó a acomodar los disensos, es obvio que no los resolvimos, pero entendimos la trascendencia de promover que ciertas personas hablaran y se sintieran reconocidas, mientras que para otras el desafío era aprender a escuchar y a no dominar la conversación.

La interseccionalidad brindó pautas para "pensar a través de la arquitectura completa de inequidades estructurales y de la asimetría en las oportuni-
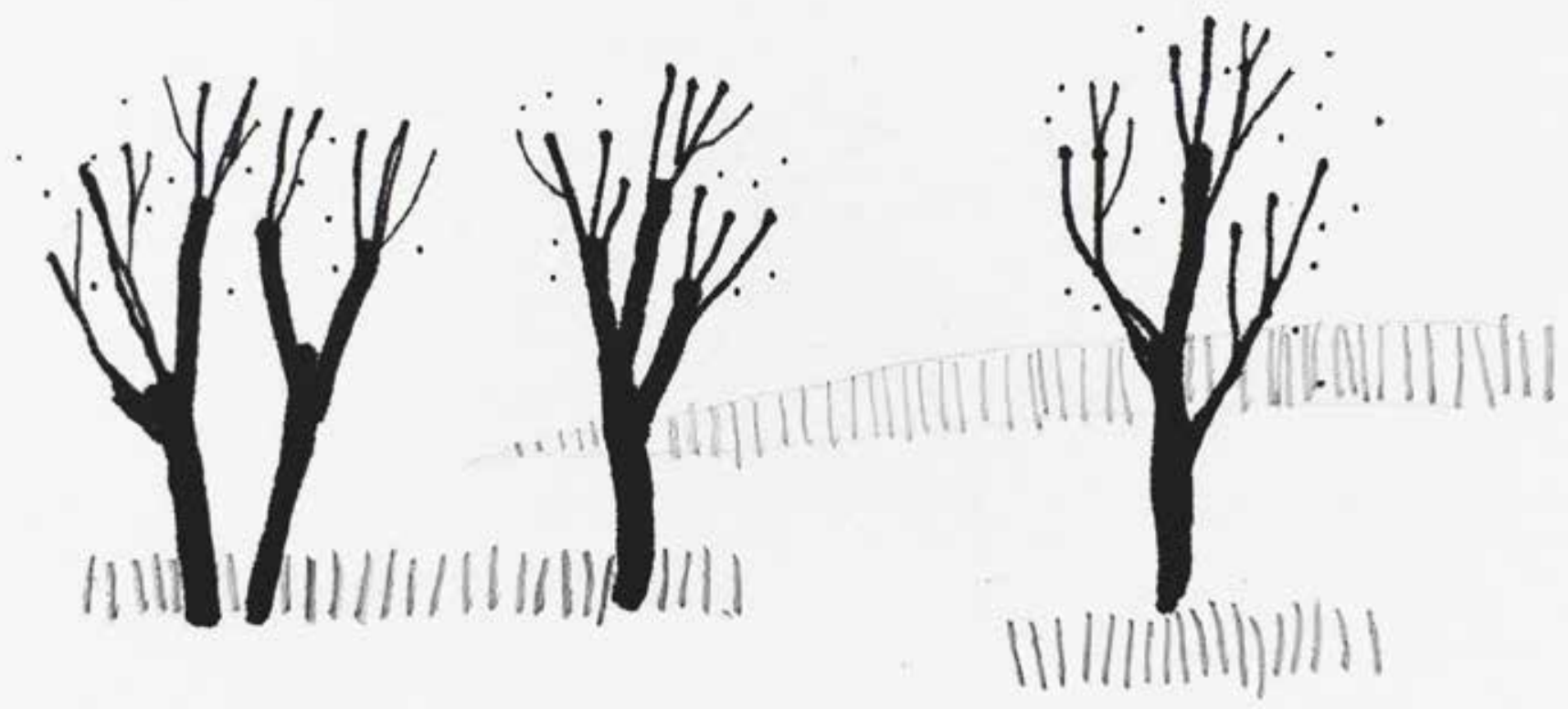
dades de vida" (May, cit en Hill Collins, 2019: 118). Hicimos un esfuerzo especial por reconocer cómo nuestras experiencias $-\mathrm{y}$ las de los actores estatales y no estatales- están influidas por las jerarquizaciones que imponen sistemas de poder como el patriarcado, el colonialismo, el capitalismo y el nacionalismo. Y, por lo tanto, identificar que la desaparición de migrantes, así como los obstáculos en su búsqueda y exigencia de justicia, tienen causas y consecuencias interconectadas con el color de piel, nivel educativo, clase económica, género, edad, preferencias sexuales, nacionalidad, etcétera, tanto de las y los migrantes que son desaparecidos como de sus familias, e incluso de los actores solidarios y estatales que intervienen. ${ }^{4}$

También significó otro camino para reconocer a la experiencia y la acción social como lugares de teorización. La intelectual Patricia Hill Collins (2019) propone que las experiencias de opresión llevan a los sujetos que la viven a desarrollar todo tipo de estrategias para desmontarla, incluida la generación de conocimiento; desde esta mirada, la interseccionalidad amplía el perfil de personas, métodos y fuentes capaces de teorizar, es más, establece la relevancia de atender esos saberes que ya existen, pues son los que dan luz sobre dominaciones que otros no alcanzan a ver, ya que las naturalizan o no les impactan de manera negativa.

Otros aportes de los feminismos negros estadounidenses fueron particularmente útiles, las reflexiones de bell hooks ayudaron a pensar a la familia no sólo como una de las instituciones más violentas que existen (Scheper-Hughes y Bourgois, 2004: 3), de la cual muchos migrantes huyen, sino también como un refugio y espacio de desobediencia ante las opresiones (hooks, 1990). Mientras que los feminismos comunitarios de Bolivia y Guatemala enseñaron a mirar las resistencias y autonomías que se escriben desde la vida cotidiana (Paredes, 2013: 38 y Tzul Tzul, 2019), uno de los temas que las y los compañeros salvadoreños designaron como centrales. Además, sus textos son ejemplos de ejercicios que, aunque escritos por individuos, representan las reflexiones de colectividades.

Por las características de los problemas abordados, la investigación se construyó como una etnografía multisituada (Marcus, 2001). Se analizaron recur- sos, materiales y simbólicos, que circulan entre los actores de Centroamérica, México y Estados Unidos, contexto transnacional donde sucede la migración, la desaparición, la búsqueda y la exigencia de justicia. Lo que permitió reconocer que los familiares son sujetos móviles no sólo porque se desplazan de un territorio geográfico a otro, sino porque ejercen roles y participaciones diferenciadas según cada escenario.

Por ejemplo, si bien las madres encabezan los discursos y eventos públicos por los desaparecidos, esto no significa que ocupen el mismo lugar protagónico en la toma de decisiones dentro de sus familias, sus colectivos o con los actores solidarios. Situar el alcance/ impacto de las diferentes posiciones que ocupan las y los familiares de migrantes desaparecidos fue fundamental para entender la efectividad de las búsquedas $\mathrm{y}$ exigencias de justicia.

Rappaport (2008) afirma que optar por otras formas metodológicas para hacer antropología no es sólo una cuestión ética, sino también una oportunidad para revitalizar y nutrir la disciplina. Coproducir teoría junto con las personas y comunidades con quienes trabajamos posibilita que se construyan nuevas agendas de investigación, y eso fue justamente lo que sucedió con los integrantes de Cofamide.

Aparte de proponer el análisis de las relaciones de poder entre actores solidarios, aspecto fundamental para fortalecer el potencial contrahegemónico de su proceso organizativo, Cofamide también visibilizó la importancia de que los actores solidarios miremos la micropolítica de su lucha, es decir, atendamos las prácticas y relaciones íntimas, sin las cuales sería imposible pensar en una presencia pública:

Quieren estar en las Caravanas, ${ }^{5}$ en las marchas, en los viacrucis, cuando vamos al MAE, ${ }^{6}$ pero no cuando tenemos que agarrar varios trabajos para juntar para venir o sacar los pasaportes. Quién pregunta si nos regresamos caminando de las reuniones, o algún familiar se enferma por la angustia de no saber, que nos piden dinero, nos tenemos que ir de la casa por las amenazas, que ya enterramos pero seguimos llorando, a veces no sabemos si vamos a poder seguir [comunicación personal, Esperanza, 2017].

4 Un análisis sobre este tema a nivel latinoamericano se puede consultar en Baraybar y Blackwell, 2014.

5 Caravanas de Madres Centroamericanas que desde 2005 salen de Honduras, Guatemala, El Salvador y Nicaragua hacia México para buscar a sus migrantes y sensibilizar sobre la problemática de la desaparición. Es sin duda la acción colectiva de los comités centroamericanos más mediática y estudiada. Más información puede verse en <https://movimiento migrantemesoamericano.org/>.

6 Mecanismo de Apoyo Exterior Mexicano de Búsqueda e Investigación, "ayuda a que las víctimas migrantes y/o familiares accedan desde el país donde se encuentran a las instituciones del Estado mexicano encargadas de investigar los delitos del orden federal que se cometen en territorio mexicano contra personas migrantes" (FGR, 2020). 
La academia tiende a concentrarse en las acciones colectivas, en la parte pública y más visible. No menosprecio esta aproximación, pues sin duda dichas investigaciones se sitúan en contextos donde la batalla consiste en el reconocimiento de las familias como sujetos políticos y reivindicar sus justos reclamos. En este sentido, resaltan los aportes de Salazar Araya (2016), Martinelli Leal (2017), Vargas Carrasco (2016), Robledo y Garrido (2017) y Varela (2012), cuyas investigaciones abordan cuándo, cómo y para qué se producen las prácticas de movilización de los colectivos de familiares de desaparecidos nacionales y migrantes.

Pero es precisamente porque se trata de aportes exhaustivos que es esencial no sólo imitarlos sino complementarlos mirando lo señalado por las familias salvadoreñas. Lo que Melucci (1989) denomina la dimensión subterránea de los movimientos sociales, la parte íntima donde la gente se deja afectar de manera continua para sostenerse en los múltiples espacios de lucha y resistencia. Lo que abre también la oportunidad de revisar las intervenciones/acompañamientos que los aliados llevamos a cabo para apoyar en el sostenimiento de la participación activa de las familias.

La dimensión colaborativa de la investigación nos permitió producir "colectivamente vehículos conceptuales que aprovechan tanto el cuerpo de la teoría antropológica como los conceptos desarrollados por los interlocutores" (Rappaport, 2008: 6). Con todas las variantes e impurezas metodológicas que ya se describieron, las y los compañeros salvadoreños abrieron un camino poco explorado que aporta a la revitalización de las ciencias sociales, el cual consiste en responder preguntas como:

- Por qué hay familias que no buscan

- Qué hacemos cuando no coincidimos con nuestros aliados; qué hacemos cuando nos sentimos excluidos, usados, saturados

- Por qué hay más apoyo y financiamiento a la judicialización que a la búsqueda de los desaparecidos

- Cómo impulsar las búsquedas en vida

- Cómo encontrar apoyo y asesorías para resolver los problemas económicos, administrativos y patrimoniales que se derivan de la desaparición, los cuales aumentan profundamente la pobreza y precariedad de las familias

- Cuál es el papel de los niños y jóvenes en las búsquedas y las exigencias de justicia
De este modo, el proceso de la investigación no se redujo a una sola forma de hacer, cada coyuntura requirió respuestas diferenciadas. Las metodologías mencionadas conviven al mismo tiempo y se vuelven protagonistas según las necesidades que van surgiendo, construyendo un método mixto o impuro. Lo único que se sostiene son los intentos por superar las dicotomías teoría-práctica e investigador-sujeto de estudio, lo que implicó dialogar de forma ininterrumpida, renegociar los conflictos y aprender a seguir colaborando aun cuando no coincidiéramos.

Cierro este apartado insistiendo en que la construcción de una investigación donde los actores no académicos sean coinvestigadores no tiene por qué encajar en todas las circunstancias. Por ejemplo, el trabajo de campo de mi doctorado lo llevé a cabo simultáneamente con Cofamide y con cinco comités hondureños; sin embargo, la relación de confianza y cercanía para desarrollar un trabajo colaborativo surgió de manera exclusiva en El Salvador.

En Honduras implementé métodos tradicionales y, para identificar los temas que les eran más significativos, recurrí a entrevistas abiertas que empezaban con la pregunta: ¿cómo eras de niño/niña?, y ya no sugería un nuevo tema, me limitaba a preguntar / comentar sobre lo que iban compartiendo. Estas conversaciones mostraron el espectro amplio en el que se inserta la desaparición más allá de la búsqueda y la exigencia de justicia, y la heterogeneidad de [re]acciones de los integrantes de las familias según su edad, género, posición socioeconómica, estatus migratorio, etcétera Ambas metodologías -el ensamblaje de métodos y las herramientas tradicionales-fueron útiles y pertinentes dependiendo de cada escenario.

Al revisar la literatura sobre desaparición se encuentran esfuerzos valiosos donde académicos y periodistas prestan sus servicios especializados, ${ }^{7} \mathrm{y}$ el hecho de que sigan siendo los expertos no resta impacto a los resultados. Además, usar metodologías colaborativas / participativas no garantiza que se aporten beneficios para los colectivos, pues muchas veces los investigadores militantes imponen sus puntos de vista sobre lo que es correcto o lo que el colectivo debería hacer (First Nations Centre, 2005: 3); además, andamos a un ritmo desaforado que la gente no puede ni tiene por qué seguir, y eso perjudica, en vez de apoyar, los procesos internos de los colectivos (Rappaport, 2008).

Hay escenarios donde las familias y los migrantes se sienten cómodos con la jerarquización de roles entre

\footnotetext{
7 Por ejemplo: Grupo de Investigaciones en Antropología Social y Forense (GiASF); Ciencia Forense Ciudadana; A dónde van los desparecidos, y El Faro.
} 
representantes y representados. El problema aparece cuando todos los que nos solidarizamos ignoramos la explícita petición de sumarnos, desde donde podamos, a fortalecer su presencia protagónica y en lugar de eso hablamos por ellos.

\section{¿Cómo intervenimos en las relaciones de poder que dificultan la colaboración?}

Construir la investigación colectiva conllevó diversos retos. Para empezar, la relación nunca fue espontáneamente horizontal, al contrario, implicó poner especial atención en que tanto hombres como mujeres participaran, en que mi opinión no tuviera más peso que la de los demás, que integráramos a las personas más tímidas, más jóvenes, a quienes no piensan igual que la mayoría.

En los espacios colaborativos / participativos yo fui responsable de planear e implementar talleres con técnicas de educación popular que generaran discusiones, cuestionamientos y que mantuvieran la mente y el cuerpo presentes, además de apoyar con la sistematización de lo hablado. Trabajar desde la educación popular permitió que las conversaciones, que en un principio fueron detonadas por actividades prediseñadas, se retomaran con soltura en otros momentos.

Los diferentes ritmos y urgencias fueron otro gran desafío, pues mientras yo tuve una beca del Consejo Nacional de Ciencia y Tecnología (Conacyt) y pude dar mi dedicación exclusiva, las y los compañeros salvadoreños estaban saturados de jornadas laborales, tanto aquellas encaminadas a conseguir recursos económicos para sostenerse como las vinculadas con el Comité y / o con otros espacios de militancia política o apoyo comunitario. Y para las mujeres se agregan además las tareas de cuidados, pues a ellas se les impone la responsabilidad de encargarse de las actividades para la reproducción de la vida familiar. Esto no es menor si tomamos en cuenta que 82 por ciento de las personas que integran Cofamide son mujeres de entre 45 y 85 años, todas con carga de trabajo de cuidados y del hogar no remuneradas (Beltrán, Interiano y Toche, 2020).

En este contexto es necesario revisar constantemente que la colaboración no se dé a tiempos acelerados, no forzar procesos que las familias no puedan seguir más que como receptoras de información o dadoras de testimonio, y no como parte integral de la toma de decisiones de la investigación y de los análisis. Sin cuidar que la participación esté presente en todo momento, de la forma en que puedan y quieran, se corre el riesgo de estar replicando prácticas extractivistas, pero nombradas con términos que las disimulen.

Para evitar el arrastre de actividades definimos calendarios acordes a los distintos ritmos, aunque eso supuso que los procesos se alargaran más allá de los plazos establecidos en un principio, siempre con la disposición de posponer y avanzar más lento si hacía falta. Aparte de mi beca Conacyt, ninguna otra persona recibió compensaciones económicas por su participación en la investigación, pero sí decidimos hacer todo lo posible por garantizar condiciones dignas para realizar los trabajos colectivos.

Otra de mis tareas clave fue elaborar proyectos y contender en convocatorias de la academia y de la sociedad civil para financiar nuestras reuniones y actividades, e intercalar los encuentros presenciales con conversaciones a distancia a través de aplicaciones de comunicación digital. Parte de mi tarea ha sido explicar a quien nos ha financiado que, para mantener la colaboración, es indispensable flexibilizar los tiempos de entrega de productos y muchas veces modificar lo planteado originalmente.

Además de la diferencia entre los ritmos, otro reto que atravesó todo el proceso fue armonizar/entrelazar las diversas formas de investigar que tenemos. Al principio este aspecto no fue tan claro, puesto que sólo yo sistematizaba las discusiones colectivas; las escribía respetando la expresión de las personas, pero también lo hacía bajo ciertas normas que encajaran con lo esperado en un documento académico. Cuando las compañeras y los compañeros iniciaron sus propias investigaciones, y se entusiasmaron con "ser más parte de este libro", "con sacarlo adelante", fue evidente que planteaban no sólo otros temas de investigación, sino también otras formas de investigar.

Por ejemplo, mientras que las investigaciones académicas clásicas parten de un tema y de unos objetivos delimitados, y el trabajo de campo está encaminado a buscar personas que puedan hablar sobre ese tema, para los familiares involucrados en este proceso la investigación se centra en las personas a las que quieren acercarse, conocer y entrevistar, hablan de lo que las y los entrevistados consideran esencial y desde ahí analizan similitudes, diferencias y posibles conexiones

Además, las y los salvadoreños no segmentan los temas, como sí lo hace la academia, sino que centran su atención en las interrelaciones para conocer los contextos amplios que las personas entrevistadas construyen y en los que se insertan. Por último, en sus análisis los contrastes tienden a ser tomados como complementarios y no como opuestos; he profundizado en este tema en otros artículos (Martínez Castillo, 2020) donde explico cómo para los familiares de mi- 
grantes desaparecidos con quienes he colaborado la búsqueda y la judicialización de los casos y el enfoque humanitario y de derechos humanos no son categorías opuestas entre las que hay que elegir, sino estrategias que componen el espectro amplio de opciones para encontrar a sus seres queridos y construir justicia.

En este sentido, las investigaciones de las y los salvadoreños mostraron un vacío importante en el acompañamiento que estaba llevando a cabo. Es cierto que me había esforzado por revisar que mi opinión no fuera la decisiva y que se hablara de lo que ellas y ellos querían y no de los temas que a mí me parecían centrales, pero había encauzado las conversaciones desde mi forma de investigar, desde mis normas teóricas y metodológicas, sin siquiera plantearme la posibilidad de que quisieran hacerlo desde otros lados.

Ya para ese entonces las familias habían señalado que se sentían presionadas por los actores solidarios para que asumieran discursos y prácticas que no siempre les parecían los más urgentes. De las 20 personas involucradas sólo uno, Enrique, estaba convencido de que el discurso de derechos humanos engloba todo lo que las familias exigen, para los demás éste es un lenguaje potente pero limitado, pues excluye acciones que a ellos les gustaría llevar a cabo, pero que han tenido que aprender y usar para que quienes los respaldan mantengan su apoyo y para que los gobiernos les hagan caso.

Imponer el lenguaje de derechos humanos como régimen ordenador de toda la lucha y no contemplar otras formas de investigación son ejemplos de prácticas opresivas/coloniales que ejercemos sobre las familias de migrantes desaparecidos de El Salvador. Yo había criticado cuando estas acciones eran realizadas por ONG, organismos humanitarios, financiadoras; sin embargo, no había sido consciente que desde mi práctica también estaba replicando la violencia epistémica (Santos, 2006), que consiste en asumir que mis conocimientos tienen validez universal y que las familias deben adaptarse a mis formas, abandonando así sus propias maneras de hacer las cosas. Como plantea Segato (2018), si algo caracteriza a la colonialidad es lo disgregador, lo binario, que sólo acepta un modo de hacer las cosas, frente a los pensamientos no occidentales que son agregadores, duales, donde posturas opuestas o diferentes pueden convivir sin que se anulen.
Para buscar ideas sobre cómo entretejer diferentes formas de investigar me acerqué a experiencias de investigaciones colaborativas / participativas, y en ese contexto identifiqué que las colaboraciones suelen hacerse con dos perfiles de grupos. Por un lado, con aquellos que manejan el lenguaje académico hegemónico, lo que facilita el diálogo y evita el periodo de reacomodo para encontrar espacio para los distintos saberes. Y, por el otro, con grupos que, si bien están fuera de la academia, tienen una identidad sólida y claridad sobre el valor de sus propios conocimientos; ${ }^{8}$ incluso algunos, en especial pueblos afro y amerindios, feministas y movimientos sociales, que además de tener una identidad sólida consideran a la investigación como parte fundamental de sus procesos de resistencia y lucha.

Que los grupos tengan claridad sobre sus propias formas de hacer investigaciones, o por lo menos estén en proceso de recuperar/reconfigurar esas maneras de saber-hacer, facilita la creación colectiva con externos, ya que obligan a poner los saberes académicos en discusión con los de ellos, a través del diseño previo de parámetros para afrontar la asimetría de actores, la diferencia de intereses, las expectativas de los resultados y los conflictos.

Un ejemplo es el del Proceso de Comunidades $\mathrm{Ne}$ gras (PCN) ${ }^{9}$ de Colombia, quienes aprovecharon la convocatoria de 2007 de la Asociación de Estudios Latinoamericanos (LASA) para presentar una propuesta de investigación con base en la noción de otros saberes, con sus propias preguntas y objetivos, que surgieron como resultado de las discusiones en el interior de su organización a nivel nacional. Incluso detallan condiciones metodológicas para determinar en qué casos acceden a colaborar con investigadores externos, qué requisitos deben cumplir y qué temas abordar si esperan su participación (Castillo et al., 2013: 128).

Las Primeras Naciones Canadienses (First Nations Centre, 2005) también han elaborado protocolos de investigación, donde describen los rasgos de una investigación dañina para las comunidades, explican experiencias con académicos de corte extractivista y enlistan las condiciones que ponen a todo aquel que quiera investigar con ellos.

Mientras tanto, si bien las y los compañeros salvadoreños tienen una identidad sólida como familiares de migrantes desaparecidos, y reconocen que su lucha por la verdad y la justicia ha sido un proceso de aprendizaje que los ha llevado a conocer y manejar

8 Como ejemplos de este tipo de colaboración están las investigaciones de Fals Borda, Rappaport y Jimeno que se citan en este texto.

9 “Organización política nacional afrocolombiana, que agrupa 120 organizaciones de base -mujeres, jóvenes, grupos culturales, consejos comunitarios, colectivos tanto urbanos como rurales- que reivindican los derechos de las comunidades negras" (Castillo et al., 2013: 128). 
términos y situaciones que jamás imaginaron, aún no se sienten con la confianza para expresar algunas de sus opiniones, en especial si no concuerdan con la mayoría.

Las violencias epistémicas colocan a los conocimientos producidos por las familias, en no pocas ocasiones, como conocimientos subordinados frente a los saberes de los actores solidarios. Lo que mina la confianza de las personas, pues aquellos aportes disidentes de los marcos hegemónicos de los derechos humanos, la ayuda humanitaria, el acompañamiento psicosocial, la antropología forense, etcétera, tienden a ser considerados como insuficientes o inadecuados para desestabilizar las instituciones legales y paralegales que desaparecen a los migrantes.

Los actores solidarios nos inclinamos a apoyar aquellas ideas que concuerdan con lo que consideramos correcto y a sancionar o ignorar las que se salen de nuestros discursos. Aquí es fundamental recordar que para los familiares de migrantes salvadoreños desaparecidos las redes transnacionales de personas y grupos solidarios amén de ser importantes, son, en muchos casos, indispensables para buscar y exigir justicia en países de los que no son ciudadanos, y por ello no pueden simplemente prescindir de los actores solidarios que no reconocen sus aportes.

Hay elementos adicionales que repercuten en el modo en que los conocimientos de las y los salvadoreños son recibidos; por ejemplo, cuando he compartido con actores solidarios que los sueños de los familiares son una forma de obtener información sobre sus desaparecidos, la primera reacción es cuestionar esta afirmación bajo el argumento de que ellos son mestizos, no indígenas: "si fueran indígenas se podría usar como argumento en peritajes antropológicos, se ha hecho mucho, para respaldar reparaciones, pero tienen que ser indígenas o afrodescendientes, si no, veo difícil que sirva" [anónimo, integrante de ONG mexicana, conversación junio 2019].

Como las familias salvadoreñas no cumplen con el estereotipo de lo que es el otro, se cierra la puerta a sus saberes que provienen de sistemas de producción de conocimiento diferentes a los occidentales/ hegemónicos. Entonces, ¿qué pasa con los saberes de las personas que no responden al perfil de lo que se espera que sea el otro indígena o el otro afro, pero tampoco se identifican con el lenguaje que usan las ONG y la academia?

Premiar los saberes similares y castigar los distintos ocasiona que haya familiares que prefieran no compartir lo que piensan o descarten sus opiniones frente al riesgo de perder la ayuda económica, la asesoría legal, o el acompañamiento psicosocial que reciben, o a ser expulsados del grupo. En este sentido ha sido fundamental darle espacio y atención a todas las opiniones al margen de si coinciden o no con lo que yo pienso o con lo que la mayoría del grupo plantea.

Para quien facilita y participa en espacios de investigación colectiva el objetivo es encontrar de qué manera lo que todos sienten/piensan se entrelaza y se relaciona, y no omitir lo que nos parece desatinado, imprudente y fuera de lugar. El reto es ver las conexiones donde parece que no las hay, para que todos y todas estemos dentro del proceso, y atender con la misma dedicación tanto las propuestas que concuerdan con nuestras apuestas políticas como las que no.

\section{¿Quiénes han hecho cosas similares y qué aprendemos de sus experiencias?}

En esta búsqueda apareció el trabajo de Jimeno, Castillo y Varela (2011) con la comunidad Kitek Kiwe del Cauca, Colombia. Despertó nuestro interés porque los procesos de reorganización y recuperación de la memoria sobre la matanza de la que fueron víctimas y el posterior desplazamiento forzado resultan cercanos a las experiencias de violencia política que las familias salvadoreñas han experimentado durante generaciones.

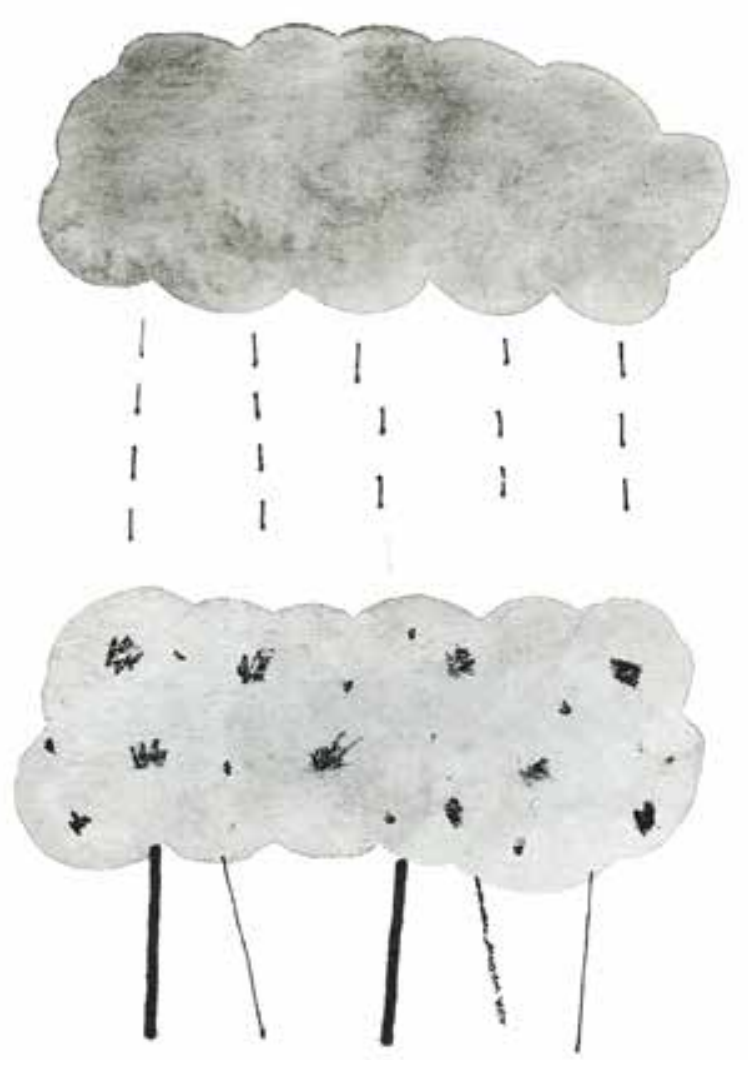


Nos fue de utilidad conocer las técnicas que desarrollaron para garantizar la colaboración activa entre los académicos y el pueblo Kitek Kiwe, como "los talleres de la memoria, las historias de vida, las conversaciones y encuentros personales, el sociodrama, el video documental y un texto divulgativo han ayudado a consolidar un lenguaje común entre antropólogos y miembros de la comunidad" (Jimeno, Castillo y Varela 2011: 282).

De su lectura entendimos que la clave de la colaboración radica en que el proceso esté determinado por la producción de resultados útiles para los participantes no académicos. En este caso diseñaron estrategias de memoria funcional (Baraybar y Blackwell, 2014: 38) es decir, procesos mediante los cuales las personas que han vivido las violencias contribuyen, de manera relevante y significativa, a la construcción de las narrativas sociales y políticas sobre lo que les pasó.

Los talleres de la memoria fueron:

una oportunidad para debatir en conjunto puntos de vista entre distintos sectores de la comunidad [...] [y un] medio para concretar reclamos de derechos, reconstruir lo que perdieron, dibujar el mapa del recorrido de los agentes de la masacre, listar las acciones emprendidas por ellos y revisar el plan actual de vida en la nueva tierra (Jimeno, Castillo y Varela, 2011: 282).

Y el conocimiento construido de manera participativa le sirvió a la comunidad para:

la dramatización pública de las memorias del Naya y para sus reclamos en el esclarecimiento de la verdad y la justicia. Es el caso del texto de la memoria, el cual miembros de la comunidad y la fiscalía usan ya como material probatorio en las indagatorias que le siguen a jefes paramilitares (Jimeno, Castillo y Varela, 2012: 37).

El ejemplo colombiano nos dio pistas importantes; sin embargo, fue difícil encontrar escritos elaborados directamente por los actores no académicos, donde su participación no fuera como entrevistados; ausencia que se repite en otras investigaciones colaborativas / participativas latinoamericanas.

En la búsqueda de escritos y/o producciones audiovisuales ideadas, diseñadas y ejecutadas por actores no académicos, pero que tuvieran el objetivo de pensar sobre la investigación, encontramos el Proyecto Andi- no de Tecnologías Campesinas (Pratec), organización civil peruana cuyas publicaciones son producidas por campesinas / os y profesoras / es rurales y de periferias urbanas que participan en sus redes. Todos los textos disponibles en su página web ${ }^{10}$ contribuyen a pensar cómo se pueden entretejer diferentes formas de investigar, pues su quehacer se caracteriza precisamente por impulsar que los miembros de las redes teoricen y conceptualicen desde sus propios conocimientos y prácticas.

Aunque a simple vista los temas de Pratec (Buen Vivir, educación intercultural, agrobiodiversidad, cambio climático) tienen poca relación con la desaparición de migrantes, los retomo porque la organización se funda con el objetivo de construir alternativas a la violencia política que de 1980 a 2000 causó la muerte de 69280 personas y la desaparición de 20329 (cVR, 2003: 13) en el país. Además, las violencias del conflicto armado peruano tienen similitudes importantes con el contexto de las desapariciones de migrantes centroamericanos en México y Estados Unidos.

El uso del terror para el control de la población es una coincidencia clave, las estrategias de Sendero Luminoso, que dinamitaba cuerpos o los dejaba en espacios públicos para ser despedazados por los animales, resuenan en las prácticas del crimen organizado mexicano, como sucedió con los migrantes asesinados y encontrados en Cadereyta, Nueva León, en 2012. El reclutamiento forzado de la población civil que se mantenía neutral al conflicto es otra característica significativa que se comparte.

En ambas guerras los actores se difuminan, entremezclan y se vuelve casi imposible identificar y comprobar quién ha hecho qué, aunque supuestamente hay bandos concretos (Sendero Luminoso vs. fuerzas del orden/crimen organizado vs. fuerzas del orden), en la práctica, una misma persona es parte de instituciones legales e ilegales de manera simultánea.

En contextos de devastación como los mencionados, reactivar prácticas e identidades andino-amazónicas para imaginar y construir relaciones que no respondan al miedo provocado por la violencia política es una estrategia referente para pensar la región mesoamericana. De hecho, ya hay experiencias en zonas como Tanzítaro, Michoacán y Chalco, Estado de México, donde comunidades que han vivido torturas, ejecuciones extrajudiciales, violaciones sexuales, extorsiones, expoliación de su territorio y desapariciones están implementando esfuerzos de reconstrucción del tejido

${ }^{10}$ Quien se interese en la abundante producción científica de Pratec puede consultar <https://pratec.org/wpress/librospratec-2/>. 
social cimentados en los fundamentos del Buen Vivir, que enriquecen con sus prácticas y saberes locales (Mendoza Zárate y González Candia, 2016).

La producción de Pratec es también una inspiración valiosa porque dialoga con múltiples experiencias y conocimientos. Es un proyecto que impulsa a campesinos, médicos tradicionales, parteras, jóvenes de zonas conurbadas, etcétera, para que teoricen, conceptualicen y escriban sobre sus saberes-haceres. Aportar al fortalecimiento de voces que han sido históricamente silenciadas es un paso indispensable para construir relaciones más justas, y es una de las principales razones por las que las y los salvadoreños decidieron participar en esta investigación colectiva, encontrar su propia voz y dimensionar el valor de sus aportes.

A partir del agravamiento de la crisis por las desapariciones, en México también han surgido otras formas de hacer investigación que enriquecieron nuestras prácticas. Por ejemplo, en 2019 el colectivo Familiares en Búsqueda María Herrera y el Centro de Estudios Ecuménicos publicaron Tejiendo esperanzas. Reflexiones junto a colectivos y familiares de personas desaparecidas en México de la Red de Enlaces Nacionales, que sistematiza los aprendizajes derivados de las Brigadas Nacionales de Búsqueda de Desaparecidos, específicamente del Eje de intervención en Iglesias y Comunidades (VV. AA., 2019).

El documento incluye textos y entrevistas realizadas por familiares de distintas regiones del país, e integra reflexiones de los actores solidarios que acompañan las búsquedas, en concreto de académicos, ong e Iglesias. Los familiares analizan la colectivización de la lucha, las formas en que la búsqueda por los desaparecidos se hermana con la defensa de la tierra y el territorio, así como el impacto que las mujeres organizadas están teniendo en los espacios públicos. Además, presentan conceptos que tendríamos que empezar a mirar con más detenimiento, como el de paz justa.

En el mismo orden de ideas, no se puede dejar de mencionar el Diplomado Desaparición Forzada en México y América Latina implementado por la Universidad Autónoma Metropolitana-Cuajimalpa (UAM-C), cuyo contenido curricular y temático fue construido entre profesores de la unidad y familiares de personas desaparecidas, quienes son también docentes encargados de impartir materias durante este proceso educativo. Resalta asimismo la participación de la UAM-C apoyando a los colectivos mexicanos en las brigadas de búsqueda, lo que ha implicado que la universidad salga de sí misma, un ejemplo de la potencia de la colaboración cuando los actores se atreven o son obligados a moverse de sus estructuras rígidas y aisladas para participar y aportar en procesos vivos.

\section{Ideas de cierre}

No hay respuesta única a las preguntas que abren esta conversación, a lo largo del texto se expuso una de las muchísimas alternativas que se están gestando para pensar la realidad actual, que de ninguna manera se propone como instructivo, a lo mucho puede ser inspiración.

Esta colaboración inició cuando las y los salvadoreños propusieron modificar los temas y preguntas de investigación para que el proceso fuera realmente significativo para ellas y ellos. A partir de ese momento se apropiaron de la investigación y aportaron no sólo materia prima -testimonios o entrevistas-, sino también analizaron su información y la de los demás, sus propias prácticas, diseñaron conceptos que visibilizan temas y relaciones importantes para sus luchas, pero que no eran reconocidos y evaluaron de qué modo lo producido podía fortalecer sus objetivos políticos.

Para sostener su involucramiento protagónico recurrimos a la investigación acción participativa, a metodologías colaborativas, feministas negras y comunitarias y a etnografías multisituadas, en especial la interseccionalidad fue un eje que enriqueció cada uno de los pasos del proceso, para evitar la repetición de violencias epistémicas en el interior de nuestra colaboración y para guiar el análisis de los temas de investigación.

En este caminar, nos dimos cuenta de que la colaboración también revitaliza a la academia, pues las familias colocaron temas prácticamente no estudiados en el contexto de desaparición de migrantes, pero fundamentales para entender la complejidad de la problemática y guiar intervenciones solidarias más oportunas. Por ejemplo, las relaciones de poder dentro de los actores solidarios, la micropolítica que sostiene la lucha pública, los problemas/conflictos patrimoniales, legales, burocráticos que la desaparición desata, pero que no han sido abordados con la urgencia que merecen, incluso preguntarse por qué hay familias que no buscan y qué hacer para apoyarles.

La diferencia de tiempos, recursos y formas de investigar fueron los principales desafíos para mantener la colaboración, más o menos, horizontal. En especial las reflexiones sobre las distintas formas de investigar dirigieron de nuevo la mirada a las relaciones de poder-dominación entre actores amigos, aquí llamados solidarios / aliados, es decir onG, organismos internacionales, financiadoras, psicólogos, juristas, académicos, Iglesias, periodistas, que buscan acompañar a las familias de migrantes desaparecidos.

En este escenario, respetar, escuchar e incorporar los saberes no-hegemónicos producidos por las familias 
fue una estrategia para considerar a esta investigación como colaborativa/participativa. Pues entre las relaciones solidarias, los conocimientos de las familias que se apegan a los hegemónicos son recompensados, mientras que los disidentes se ignoran o descartan por ser considerados incapaces de desestabilizar a las instituciones que desaparecen a los migrantes, aunque en realidad no se haya probado su inefectividad.

Para no replicar las violencias epistémicas buscamos experiencias similares para aprender cómo sortearon las jerarquías de dominación implícitas en toda colaboración. Encontramos en las investigaciones encabezadas por Miriam Jimeno, en la producción de saberes de la organización peruana Pratec y en los colectivos mexicanos de familias de personas desaparecidas estrategias concretas que nos ayudaron a resolver las manifestaciones cotidianas de dichas jerarquías.

Aprendí/aprendimos que las investigaciones pueden llegar a ser poderosos espacios de aprendizaje político, especialmente para los académicos.

\section{Fuentes}

Arribas lozano, Alberto

2018 "Knowledge co-production with social movement networks. Redefining grassroots politics, rethinking research", en Social Movement Studies, vol. 17, núm. 4, pp. 451-463 <https: / / doi.org/ 10.1080/14742837.2018. $1457521>$ [ 17 de julio de 2021]

BARAYBAR, JosÉ PABLO

Y BlACKWELL, REBECCA

2014 "Where are they? Missing, Forensics, and Memory", en Annals of Anthropological Practice, vol. 38, núm. 1, pp. 22-42 <https://doi. org/10.1111/napa.12040> [17 de marzo de 2021 ].

Beltrán, Elena, Claudia Interiano

y Maricela Toche

202 "Trabajo de cuidados en tiempos de pandemia", en Alharaca <https: / /www.alharaca.sv/ descompases / trabajo-de-cuidados-entiempos-de-pandemia/> [5 de noviembre de 20211.

Castillo, luis Carlos, libia Grueso,

Carlos Rosero y Konty Bikila Cifuentes

2013 "El Proceso de Comunidades Negras (PCN) y el censo de 2005: la lucha en contra de la 'invisibilidad' estadística de la gente negra en Colombia", en Charles Hale y Lynn Stephen (eds.), Otros saberes. Collaborative research on indigenous and afro-descendant cultural politics, School for Advanced Research Press (Global indigenous politics series), Nuevo México, pp. 127-153.

Cofamide 2017

Investigación de condiciones socioeconómicas de familiares de personas migrantes fallecidas y desaparecidas en ruta a Estados Unidos, Comité de Familiares de Migrantes Fa- llecidos y Desaparecidos de El Salvador, San Salvador, $90 \mathrm{pp}$.

Crenshaw, Kimberlé

1991 "Mapping the margins. Intersectionality, identity politics, and violence against women of color", en Stanford Law Review, vol. 43, núm. 6, pp. 1241-1299.

CVR

2003 “Anexo 2. ¿Cuántos peruanos murieron? Estimación del total de víctimas causadas por el conflicto armado interno entre 1980 y el 2000”, en Resumen Informe Final de la Comisión de Verdad y Reconciliación, Comisión de la Verdad y la Reconciliación, 55 pp.

Fals-Borda, Orlando

1978 "Por la praxis: el problema de cómo investigar la realidad para transformarla", en Revista Serviço Social \& Sociedade, año 4, núm. 11, pp. 29-62.

FGR-Fiscalía General de la República

2020 "Unidad de Investigación de Delitos para Personas Migrantes - UIDPM", en Subprocuraduría de Derechos Humanos, Prevención del Delito y Servicios a la Comunidad <https:// www.gob. $\mathrm{mx} / \mathrm{fgr} /$ acciones-y-programas / unidad-de-investigacion-de-delitos-parapersonas-migrantes-uidpm\#: :text=Cuenta\% 20 con $\% 20$ el\% 20Mecanismo\% 20de,que $\% 20$ se\%20comenten\%20en\%20territorio> [8 de agosto de 2020]

First Nations Centre

2005 Ownership, Control, Access, and Possession (OCAP) or Self-Determination Applied to Research: A critical Analysis of Contemporary First Nations Research and Some Options for First Nations Communities, National Aboriginal Health Organization (NAHO), Ottawa, 37 pp. <https: / / ruor.uottawa.ca/bitstream/ 103 93/30539/1/OCAP_Critical_Analysis_2005. pdf> [5 de noviembre de 2021]

Flamtermesky, Helga

2014 "Mujer frontera. Experiencia de investigación acción participativa feminista (IAPF) con mujeres víctimas de la trata", en Athenea Digital, vol. 14, núm. 4, pp. 389-400<https: / / doi.org/ $10.5565 / \mathrm{rev} /$ athenea. $1474>$ [ 15 de noviembre de 2018].

Hill Collins, Patricia

2019 Intersectionality as a critical social theory, Duke University Press, Durham y Londres, $360 \mathrm{pp}$.

HOOKS, BELL

1990 "Homeplace (a site of resistance)", en bell hooks, Yearning: race, gender, and cultural politics, South End Press, Boston, pp. 383390.

Jimeno, Myriam, Ángela Castillo

y DANiEl VAREla

2011 "Experiencias de violencia: etnografía y recomposición social en Colombia”, en Sociedade e Cultura, vol. 14, núm. 2, julio-diciembre, pp. 275-285 <https://www.revistas.ufg.br/ fchf/article/view/17604/10555> [15 de noviembre de 2018]

Jimeno, Myriam, Ángela Castillo

Y DANIEL VARELA

2012 "Experiencias de violencia, etnografía y recomposición social en Colombia", en Jimeno, Myriam, Sandra Liliana Murillo y Marco Ju- 
lián Martínez (eds.), Etnografías contemporáneas. Trabajo de campo. Universidad Nacional de Colombia, Bogotá, 19-45. <https:// www.uneditorial.com/media/hipertexto / epub/9789587618723.pdf> [5 de noviembre de 2021].

LAW, JoHN

2004

Marcus, George

After Method. Mess in Social Science Research, Routledge, Nueva York, 188 pp.

2001 "Etnografías en/del sistema mundo. El surgimiento de la etnografía multilocal", en Alteridades, año 11 , núm. 22, pp. 111-127.

Martinelli Leal, EduARdo

2017 "A dúvida mais persistente: as formas de governo do desaparecimiento de pessoas no Brasil", tesis de doctorado en Antropología Social, Universidade Federal do Río Grande do Sul, Porto Alegre.

Martínez Castillo, Gabriela

2020 "Desafíos y tensiones en la búsqueda de migrantes desaparecidos de Honduras y El Salvador", en Íconos. Revista de Ciencias Sociales, núm. 67, pp. 75-93 <https://doi.org/ 10.17141/iconos.67.2020.4199> [ 17 de julio $2021]$.

Melucci, Alberto

1989 Nomads of the Present: Social Movements and Individual Needs in Contemporary Society, Hutchinson Radius, Londres, 280 pp.

Mendoza Zárate, Gabriel

y Jorge Atilano González Candia (COORds.)

2016 Reconstrucción del tejido social: una apuesta por la paz, Centro de Investigación y Acción Social por la Paz del Centro de Derechos Humanos Miguel Agustín Pro Juárez, México, 244 pp.

Paredes, Julieta

2013 Hilando fino desde el feminismo comunitario, Cooperativa El Rebozo, Zapateándole, Lente Flotante, En cortito que's pa largo y Alifem, La Paz, 125 pp.

RAPPAPORT, JOANNE

2008 "Beyond participant observation: Collaborative ethnography as theoretical innovation", en Collaborative Anthropologies, University of Nebraska Press, Lincoln, pp. 1-31.

RAPPAPORT, JOANNE

2020 Cowards Don't Make History: Orlando Fals Borda and the Origins of Participatory Action Research, Duke University Press, Durham y Londres, 312 pp. <https: / / doi.org/10.2307/j. ctv16qjzcx> [ 17 de julio de 2021].

Robledo, Carolina y Susana Garrido

2017 "Vidas precarias en tránsito: sin tierra para el llanto", en Desacatos núm. 53, enero-abril, pp. 150-167.

Salazar Araya, Sergio

2016 "Circular el territorio migrante. Producción social de la migración centroamericana en tránsito por México: Frontera, albergue y desaparición", tesis de doctorado en Antropología Social, Universidad Iberoamericana, México.

Santos, Boaventura de Sousa

2006 Conocer desde el Sur. Para una cultura política emancipatoria, Universidad Nacional Mayor de San Marcos/Programa de Estudios sobre Democracia y Transformación Global, Lima, 248 pp.

Scheper-Hughes, Nancy

y Philippe Bourgois (EDs.)

2004 "Making sense of violence", en Violence in War and Peace: an Anthology, Willey-Blackwell Publishing, Nueva Jersey, 512 pp.

Segato, Rita Laura

2018 "Refundar el feminismo para refundar la política", ponencia magistral presentada al Congreso Internacional Cuerpos, despojos, territorios: la vida amenazada, Universidad Andina Simón Bolívar, Quito.

Tzul Tzul, Gladys

2019 "Sistemas de gobierno comunal indígena: la organización de la reproducción de la vida", en Producir lo común. Entramados comunitarios y luchas por la vida, Traficantes de Sueños, Madrid, pp. 171-183.

Varela, Amarela

2012 "Del silencio salimos: la Caravana de madres hondureñas en México. Un ejemplo de resistencias en clave femenina al régimen global de fronteras”, en Alejandra Aquino, Fred Decossé y Amarela Varela (coords.), Desafiando fronteras: control de la movilidad y experiencias migratorias en el contexto capitalista. Sur + Ediciones / Frontera Press, Oaxaca, pp. 175- 186.

Vargas Carrasco, Felipe de Jesús

2016 "La dignidad no tiene fronteras: la lucha trasnacional por el respeto a los derechos humanos de las personas migrantes en tránsito por México", tesis de maestría en Sociología Política, Instituto de Investigaciones Dr. José María Luis Mora, México.

VV. AA.

2019 Tejiendo esperanzas. Reflexiones junto a colectivos y familiares de personas desaparecidas en México de la Red de Enlaces Nacionales. Familiares en Búsqueda María Herrera/Centro de Estudios Ecuménicos, México, 65 pp. 